DOI https://doi.org/10.18551/rjoas.2017-08.14

\title{
ANALYZING AND MODELING THE ROLE OF HUMAN RESOURCE INFORMATION SYSTEM ON HUMAN RESOURCE PLANNING AT HIGER EDUCATION INSTITUTION IN INDONESIA
}

\author{
Susilo Heru*, Astuti Endang Siti, Wiyata \\ Department of Business Administration, Faculty of Administrative Science, \\ University of Brawijaya, Indonesia \\ *E-mail: herususilo@ub.ac.id
}

\begin{abstract}
The challenge of Human Resource Management in Higher Education Institutions is how to plan, organize, and assess the performance of human resources so as to contribute as much as possible to the achievement of high quality education objectives. To answer these challenges, the role of Human Resources Information System (HRIS) is needed to facilitate leadership both at the university and faculty level in preparing the needs planning and utilizing the advantages of human resources. This study aims to analyze the role of HRIS in human resource planning, especially in the stages of needs planning activities, recruitment and selection, human resources development, promotion and promotion, and assessment of work and remuneration. The output of research resulted in the form of HRIS-based human resource planning concepts for Higher Education Institutions. The research method was designed using qualitative descriptive approach. Data collection is done through observation technique and interview with research location in University of Brawijaya. The results show that the existing HRIS has not played an optimal role because the function of the system is still limited as a data gathering medium and the submission of employment reports that have not been able to contribute as a decision support system for leaders in HR planning.
\end{abstract}

\section{KEY WORDS}

Role, planning, higher education, institution.

Human Resources (HR) is an important factor in running the wheel of the organization The challenge of Human Resource Management (HR) in Higher Education Institutions is how to plan, organize, and assess the performance of human resources owned so as to contribute as much as possible to the achievement of high quality education goals. As universities grew bigger, with a growing number of students it was demanded to be able to provide better services, faster, and accurate although the number of human resources owned is limited. Therefore, the role of Human Resource Information System is very necessary to facilitate the leadership in preparing the needs planning and utilizing the benefits of human resources owned. HRIS is a systematic procedure for collecting, storing, maintaining, displaying and validating data required by the organization on human resources, human resource activities, and organizational unit characteristics (Kovach et al., 1999).

\section{LITERATURE REVIEW}

Human Resource Planning is a process that ensures an organization has the right amount of human resources and type at the right place and time and can streamline and streamline the task and achievement of all organizational goals (Nagendra and Deshpandi, 2014). Mondy \& Noe (1995) defines HRP as a process that systematically examines the state of human resources to ensure that quantities and qualities with appropriate skills will be available when they are needed. Cherian (2011) defines HRP as the process of forecasting demand and supply of human resources by recruiting the right employees, and having the right skills according to the needs of the organization. HRIS by Kavanagh, Thite, and Johnson (2012) is defined as a system used to search, store, process, reproduce, and distribute information related to human resources within the organization. HRIS (Human 
Resources Information System) is a system used to acquire, store, manipulate, analyze, retrieve and distribute relevant information with human resource organizations. McLeod (2001) reveals the conceptual system used in managing personnel called the Human Resource Information System (HRIS). HRIS serves to accelerate decision-making, development, planning, and HR administration processes because data is easily stored, updated, classified, and analyzed (Sadri and Chatterjee, 2003).

Nagendra and Deshpande (2014) undertook research on Human Resource Information Systems (HRIS) in HR planning and development in mid to large sized organizations. This study aims to identify the contribution of HRIS in the employment recruitment system to the organization, to investigate the contribution of HRIS to training and Developing the workforce of the organization, and exploring the overall contribution of HRIS in HR decision making and aligning HR strategies with organizational strategy. The study used descriptive qualitative methods, primary data were collected using questionnaires from 50 senior executives and junior managers in three organizations in Pune India. The results show that overall HRIS use has contributed greatly to the efficiency and effectiveness of HR planning.

Khera and Gulati (2012) in a research entitled Human Resource Information System and Its Impact on Human Resource Planning: A Perceptual Analysis of Information Technology Companies, conducted a study aimed at investigating the role of HRIS on HR planning in information technology organizations by taking a sample of 127 Respondents from 7 information technology companies. The research was designed using exploratory research method by taking primary data from survey and interview to employee and secondary data taken from company website, then data analyzed using SPSS statistical tool with factor analysis method. The results showed that HRIS correlated significantly to the accuracy of HR planning in several stages of HR planning including job description analysis with correlation coefficient of 568, accurate placement of employee placement accuracy of 0.892 , and the accurate identification of placement of employee by 0.677 .

Human resource planning (HRP) is generally overlooked in most organizations as the importance of HRP is not acknowledged (Vareta, 2010). Cherian (2011) defined HRP as the process of forecasting the demand and supply human resource and recruiting the correct number of employees, with right skills (as per the job) as per the need of the organization. The process of HRP was described by Pravin (2010) as seen from Figure 1.

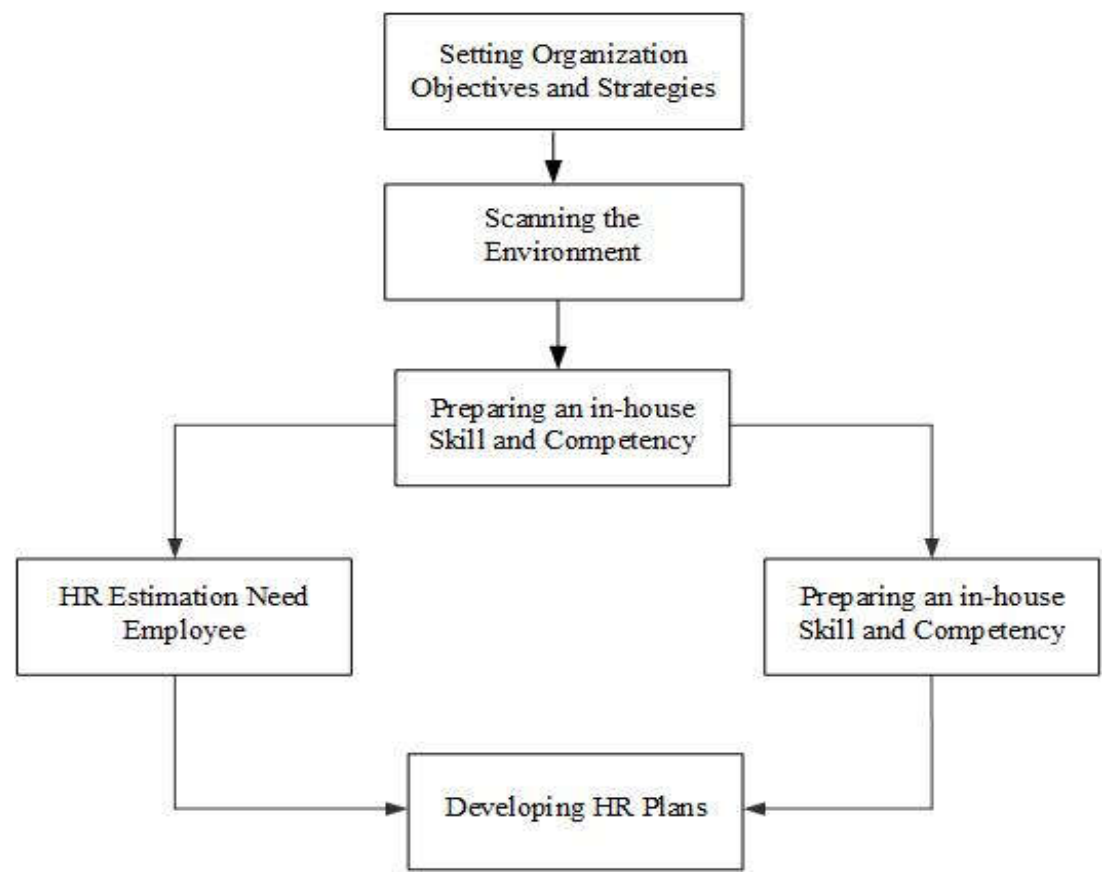

Figure 1 - Human Resource Planning Process

Source: Pravin Durai (2010), Human Resource Management, Pearson Education Publication. 


\section{METHODS OF RESEARCH}

This research is designed using descriptive exploratory approach with the purpose of describing clearly, in detail, and depth about the role of HR information system in human resource planning at one of the largest Higher Education Institutions in East Java. This method of approach allows researchers to obtain data and information from informant with the aim of building theory more than just testing (Myers and Avison, 2002). Data collection was conducted in November-December 2016 through observation techniques on existing HRIS system conditions and facilities and interviews with some of the leaders responsible for human resource development. Interviews were conducted with 15 informants including 5 leaders at top level management, 5 leaders in middle level management, and 5 leaders at low level management. Interviews were conducted semi-structured (Kvale, 1996) followed by in-depth interviews developed based on the question of the extent of HRIS's role in activities; (1) human resource needs planning; (2) recruitment and selection; (3) human resource development; (4) promotion of position; (5) performance appraisal.

The analytical technique uses a fixed comparison method between the observation results and the interview results by performing three stages of activity: preliminary analysis, formal analysis, and final data analysis (Rubin and Rubin, 1995). Preliminary analysis was conducted by observing the condition of the HRIS system, formal analysis was carried out at the time of interview based on the pre-prepared questionnaire, the final analysis was done by comparing the information of the interview result and the observation result. The result of the iterative process is further described, interpreted, and compiled the pattern of answers as material for drafting the concept model of human resource planning (Miles and Huberman, 1994).

\section{RESULTS AND DISCUSSION}

Results of Interview. Based on the results of the interview can be compiled summary as in Table 1.

Table 1 - Summary of Interview Results

\begin{tabular}{|c|l|c|c|c|}
\hline No. & \multicolumn{1}{|c|}{ Aspect } & Top Leaders & Middle Leaders & $\begin{array}{c}\text { Low } \\
\text { Leaders }\end{array}$ \\
\hline 1. & The role of HRIS in human resource planning & $\mathrm{X}$ & $\sqrt{ }$ & $\sqrt{ }$ \\
\hline 2. & The role of HRIS in Recruitment and Selection planning & $\mathrm{X}$ & $\mathrm{X}$ & $\sqrt{ }$ \\
\hline 3. & The role of HRIS in Human Resource Development & $\mathrm{X}$ & $\sqrt{ }$ & $\sqrt{ }$ \\
\hline 4. & The role of HRIS in promotion planning and promotion & $\mathrm{X}$ & $\mathrm{X}$ & $\sqrt{ }$ \\
\hline 5. & The role of HRIS in performance appraisal & $\sqrt{ }$ & $\sqrt{ }$ \\
\hline
\end{tabular}

The role of HRIS in Higher Education Institutions in human resource planning is still very low, from 15 selected informants consisting of executive officials in charge of human resources states the role of HRIS perceived benefits only when Reporting Lecturer Workload and proposing promotion of lecturers and academic staff. While for recruitment planning, selection, development of education and training, promotion, performance appraisal of education personnel, determination of remuneration has not felt its role.

Table 2 - Summary of Observation Results

\begin{tabular}{|c|l|l|}
\hline No. & \multicolumn{1}{|c|}{ System Features } & \multicolumn{1}{c|}{ Functions } \\
\hline 1. & $\begin{array}{l}\text { Human Resource Requirement } \\
\text { Planning }\end{array}$ & $\begin{array}{l}\text { - Only serves as a data source } \\
\text { - Not working as DSS yet }\end{array}$ \\
\hline 2. & $\begin{array}{l}\text { Recruitment and Selection } \\
\text { Planning }\end{array}$ & $\begin{array}{l}\text { - Only works for registration } \\
\text { - Not yet functioning as an employee selection system }\end{array}$ \\
\hline 3. & $\begin{array}{l}\text { Human Resource } \\
\text { Development Planning }\end{array}$ & $\begin{array}{l}\text { - Cannot display the list of lecturers who have to depart for further study } \\
\text { - Cannot display training needs yet }\end{array}$ \\
\hline 4. & $\begin{array}{l}\text { Planning promotion and } \\
\text { promotion of positions }\end{array}$ & $\begin{array}{l}\text { - Not working early warning system for employees whose time is } \\
\text { promoted }\end{array}$ \\
\hline 5. & Performance planning & - Has functioned as an instrument of lecturer's performance assessment. \\
\hline
\end{tabular}


The results of the observation of the system strongly support the interview result that the features available in HRIS are still intended as a medium for collecting employee data and submitting the recap report to the number of employees and the list of rank order, so it has not functioned as a decision support system in HR planning.

Analysis of the Role of HRIS in Human Resource Planning. The interview result shows that the role of HRIS is only enjoyed by leaders at low level and middle level, while for the top level leaders as decision makers have not felt the role of HRIS (Table 1). Top leaders stated: "... HRIS still not much help in human resource requirement planning. There is report of number of employees in every faculty based on education and class but there is no facility to know whether the number of lecturers and administrative staff is sufficient or not. Which sector human resources that need to be added ". Middle leaders explained; "... before preparing the HR plan requirements, every three months or six months once the head office staffing with the sub-division and staffing staff of the faculty carry out HRIS Data Reconciliation activities with the aim of synchronizing HRIS data with real data held by each faculty. Furthermore, the results of synchronization used as the preparation of Human Resource Mapping. The HR mapping report was then inputted into the Rector's Program Report ". While the operational manager or low leaders stated; "... we utilize HRIS data as material to prepare human resource planning needs. In HRIS there is a feature list of rank order report which lists the employees who have been sorted by rank / class, education, and occupation history. From there can be seen the number and qualifications of our employees as the material to make estimates of the needs of employees based on the ratio of lecturers and educational personnel to the number of students.

The statement is in accordance with the facts found during the observation that the features available in the HRIS function are still transactional and are not yet available features that can be utilized by the Executive Chiefs both at universities and faculty to estimate HR needs (Table 2). These findings indicate that the implementation of HRIS in Higher Education Institutions is still at the level of implementers of low leaders and middle leaders has not touched the needs of leaders at the top level as decision makers in the planning needs of human resources.

Analysis of the Role of HRIS in Recruitment and Selection Planning. In the process of recruitment and selection planning, HRIS's role is only felt by leaders at low level but has not contributed significantly to top level and middle level leaders. Top leader explains; "... the recruitment and selection planning process has been done manually because of many policy factors to be considered". Middle manager added "... recruitment and selection activities have not utilized HRIS to support these activities because of the GIVEN faculty of Head Office". While the low manager states; "... the process of recruitment and selection of civil servants entirely under the coordination of central committee of Kemenristek Dikti (Ministry of Higher Education and Research). Medium for Non-PNS (Civil servants) registration process began in 2015 already using the online registration system through e-recruitment application embedded in HRIS. It's just that the application for applicant to register only, the selection process is still manual because a lot of files that must be verified to continue the test in addition to written tests there are psycho-test and interviews that cannot be online ".

The observation results also prove that the existing HRIS is not yet provide adequate facilities starting from registration candidates, the selection process, until the announcement of the results of employee selection. Starting from the above problems, the ICT with the support of the university and faculty personnel department needs to conduct an audit along with any shortcomings of HRIS for further improvement and further development so that the recruitment process begins until the announcement of the selection result. Therefore, the coordination among officials in charge of human resources, among others are Vice Rector II, Vice Dean II, Head of General and Personnel Bureau, Head of Personnel Division, and Sub Division of Personnel with ICT Team is important to prepare standard procedure and requirements in process Business recruitment and employee selection, so the ICT Team can quickly build an integrated e-recruitment and e-selection information system on a single HRIS system.

Analysis of the Role of HRIS in Human Resource Development Planning. The role of 
HRIS in human resource development planning is not sufficient. It is implied from the expression of one of the top leaders who stated; "... human resources development planning is currently focused on education and training development programs. One of the educational development programs we have is the acceleration of doctors and professors because we want to improve the reputation of universities in Asia. The program certainly needs adequate data support, the problem we often do not get accurate data from HRIS anyone who has completed the task of learning, who is the task of learning, and who has not finished ". Middle manager "... at the Faculty of Animal Husbandry Insyallah always update its HRIS data so that most cannot be known who the time is dispatched S3 schools and anyone who needs to be warned anyone whose studies are not finished. While for training rarely use HRIS data because we send employees to training only when there is invitation either from Head Office or from Ministry ", low manager"... we use HRIS data to know lecturers who have time to departed further study, whereas for training activity rarely use HRIS because every opportunity and budget available we conduct training as much as possible to involve all employees in order to maintain harmony and togetherness such as conducting outbound or family gathering, as for structural training such as Pre-promotion or Leadership Training Program we propose every year whoever to be sent to participate in training ".

The result of the observation on HRIS existing condition is that the report presented is only the number of lecturers of current condition based on the level of education, the number of lecturers departing the study, the number of lecturers being studied, and the number of lecturers completed. The report is still an aggregation or recapitulation and cannot be used to monitor in detail the lecturers who have expired their studies and displays a list of lecturers who are planned to immediately carry out the task of learning. While for human resource development planning through training activities for lecturers and educational staff has not felt at all the role of HRIS by all leaders of both top leaders, middle leaders, and low leaders. Having observed that in HRIS there is not yet a feature for storing the training history of each employee as well as displaying a list of training that can be offered to lecturers and educational staff.

Analysis of the Role of HRIS in Promotion Plans. The role of HRIS to develop a promotion plan is sufficient where $57 \%$ of informants stated that HRIS had a role in preparing for promotion, while $43 \%$ stated otherwise. Top manager "... promotion, frankly, of this rank is not well planned, so far promotion proposal is done manually. I check in HRIS that there is only a list of rank order not the facilities of anyone who deserves to be promoted and whoever is taken care of promotion", Middle manager "... we use the list of order reports contained in HRIS as the basis for determining which employees are already promoted. From the list of order reports, it can also be known employees who deserve promotions based on the order of rank. If the rotation is the leader who decides when the time is rotated employees, low manage "... the employment department in cooperation with ICT will continue to try improve HRIS facilities. Currently we are still concentrating on improving the data by synchronizing the existing data in HRIS with the real data held by the faculty, so our target is to make HRIS as a valid and reliable data reference center. For promotional purposes, we use list of order reports data in HRIS which has been verified by faculty and then submitted to the assissment team ".

However, the observation of the HRIS facility shows that there is only 1 report related to promotion and rotation of the rank order. This report is used as a source of data to prepare lecturers and education personnel proposed promotion and rotation. So the information submitted is still very crude and needs to be processed again so it has not functioned as a support decision to give early warning (early warning system) to lecturers or educational staff who take care of promotion, and not yet able to provide information list of lecturers and decent educational staff Promoted.

Analysis of the Role of HRIS in Performance and Remuneration Assessment. Interview results show that most (86\%) of informants from top level management to low level management stated that HRIS has provided adequate role, while the rest (14\%) stated that it is not enough. Contribution is given primarily because in HRIS there is research facilities 
called as "Lecturer Performance Load" which proved to have functioned well so far. As for the assessment of the performance of educational staff HRIS contribution is still lacking yet there has been no standard assessment. Regarding remuneration all informants stated that they are still waiting for the implementation of remuneration system that is being done by Remuneration Team and ICT Team. Top manager "... performance is still referring to the Employee Target System (Sasaran Kerja Pegawai or SKP) issued by Indonesia's Ministry of Empowerment of State Apparatus in 2014, it's just that the system cannot be implemented in real time in the field, in other words still limited to formality. New employees will make SKP only when they want to take care of promotion because the requirement of promotion should have assessment report of SKP. So yes we have not used HRIS for performance appraisal. ", Middle manager; "... I think the lecturer's performance appraisal is standard using list of order reports instrument, which is difficult to measure the performance of educational personnel because the administrative work is rather difficult to determine the target and performance achievement. Similarly, in calculating remuneration points, remuneration of lecturers is more easily arranged its rubric than educational personnel. Until now, we are still waiting for the terms and system of remuneration calculation from the rectorate, my hope this system is integrated with HRIS so the data becomes more solid ", low manager" "... I think the lecturer's performance assessment is standard using list of order reports instrument, Measuring the performance of educational personnel because the administrative work is rather difficult to determine targets and performance achievements. Similarly, in calculating remuneration points, remuneration of lecturers is more easily arranged by its rubric than educational personnel. Until now we are still waiting for the terms and system of remuneration calculation from the rectorate, my hope this system is integrated with HRIS so the data becomes more solid". "...lecturer performance assessment through the lecturer's performance load and that the system is well established using HRIS, as for the performance of the education staff using SKP which is assigned to the attribute at the end of each year. Actually in HRIS it is available menu charging SKP but unfortunately no one has used, if SKP in HRIS filled with complete and correct remuneration calculation process is living activity of education personnel from HRIS because according to ICT team, the database is already integrated".

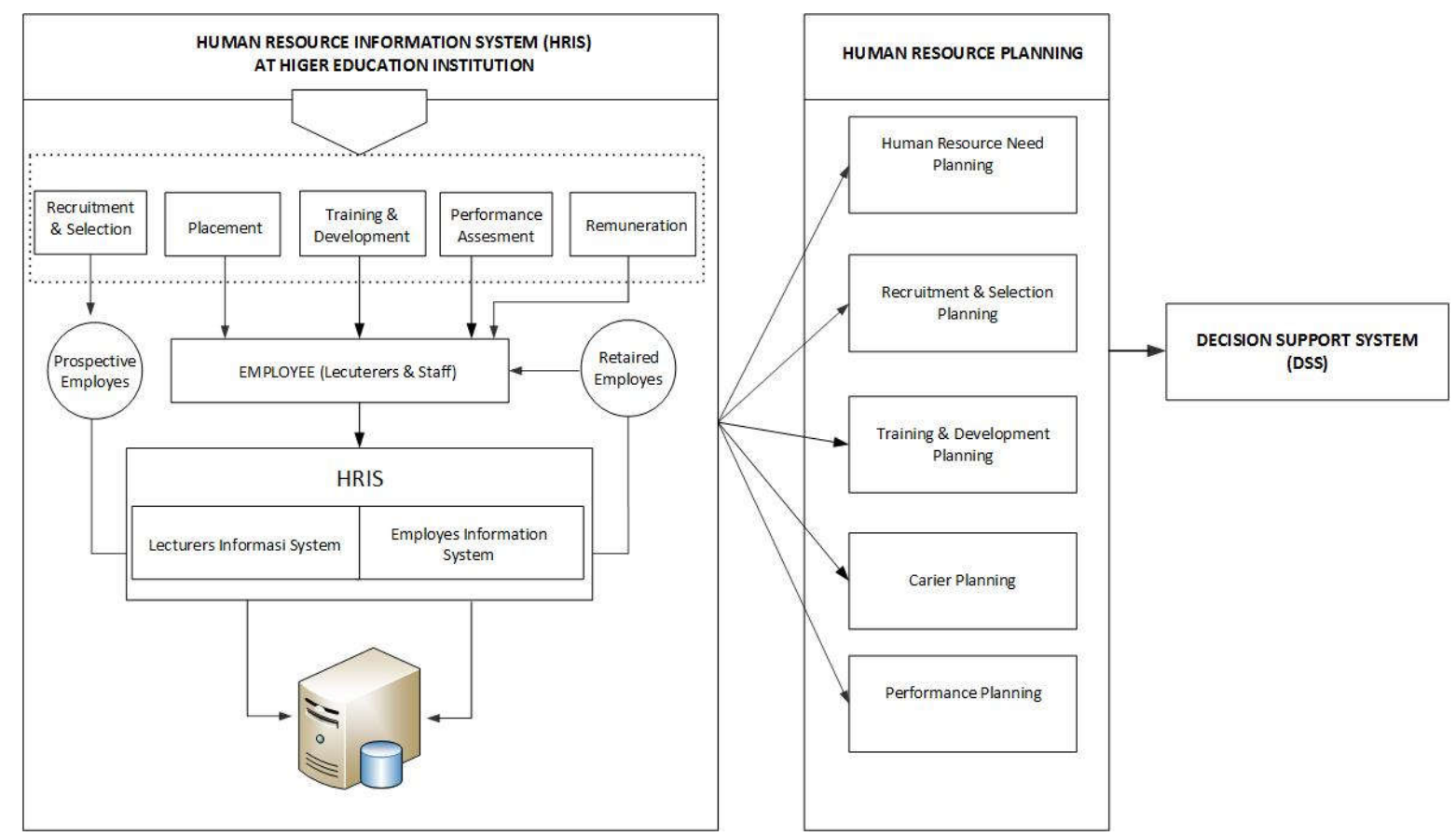

Figure 2 - HRIS Planning Concept Model based on HRIS at Higher Education Institution

The results of the system observation indicate that the features available in HRIS are complete enough from the recording of Tri Dharma (Three Principals) of Higher Institution 
activities by the lecturers concerned, the filling of list of order reports for educational activities, research, community service, supporting elements, as well as the special obligations of professors. Besides, the feature for assessment from list of order reports by Assessor has also run very well so that it can function as decision support system. Performance appraisal features for educational personnel are also available although still very simple in the form of inputs Employees Work Objective (SKP), SKP Assessment, and SKP validation. But this facility is still not utilized by all units of work proven from the results of checking to the database data is still empty. The remuneration system is apparently still in the development process proven yet to be seen in the HRIS menu, which is a remuneration simulator page for system simulation.

HRIS-Based Human Resource Planning Concept Model. Based on the results of the discussion on the role of HRIS in human resource planning in University of Brawijaya, it can be drawn up the concept model of HRM planning based on HRIS on the following institutions (Figure 2).

\section{REFERENCES}

1. Burch, J. and Grudnitski, G. (1986). Information System: Theory and Practice. John Wiley and Sons, New York.

2. Cherian, K.T. (2011), Human Resource Planning is a Systamatic Analysis of HR Needs. John Wiley and Sons, New York.

3. De Cenzo, D.A. and Robbins, S.P. (1996). Human Resource Management, 7nd Edition, John Wiley and Sons, New Jersey.

4. Durai, P. (2010), Human resource Management (Book), Pearson education Publications

5. Kavanagh, M.J., Thite, M., \& Johnson, R.D. (2012). Human resource information systems: basics, applications, and future directions. 2nd edition. United States of America: Thousand Oaks: SAGE.

6. Khera, S.N. and Gulati, K. (2012). Human Resource Information System and its Impact on Human Resource Planning: A Perceptual Analysis of Information Technology Companies, IOSR Journal of Business and Management.

7. Maier, C., Laumer, S., Eckhardt, A., Weitzel. (2012), Analyzing the Impact on HRIS Implementations on HR Personnel's job satisfaction and Turnover Intentio, Journal of Strategic Information Systems.

8. Mathis, R.L. \& Jackson, J. (2006). Human Resource Management, Edisi Kesepuluh, Jakarta, Salemba Empat.

9. McLeod, R. and Schell, G. P. (1998). Management Information Systems: Human Resource Information Systems. 10th edition. India, Prentice-Hall Publishers.

10. McLeod, R. and Anctis, Gerardine DeS (1995). A Resource-Flow Model Of The Human Resource Information System. Information Technology Management.

11. Mondy, W.R., and Noe, R. (2005). Human Resource Management. Pearson Education International, New Jersey, USA.

12. Nagendra, A. \& Deshpande, M. (2014), "Human Resource Information Systems (HRIS) in HR planning and development in mid to large sized organizations", Procedia - Social and Behavioral Sciences.

13. Noe, A.R. (2010). Manajemen Sumber Daya Manusia:Mencapai Keunggulan Bersaing Edisi-6 Buku 1. Jakarta: Salemba Empat.

14. Sadri, J. and Chatterjee, V. (2003). Building organizational character through HRIS. International Journal of Human Resources Development and Management.

15. Umamaheswari J.L (2014), Exploring internal quality of services in a manufacturing organization-A study in Lucus TVS, Chennai, Procedia Economics and Finance.

16. Werther, W.B and Davis, K. (2006). Human Resources and Personnel Management. Fifth Edition. McGraw Hill. Inc. New York. 